\title{
SEXUALITY, CONTRACEPTION AND UNINTENDED PREGNANCY AMONG FEMALE STUDENT NURSES IN CALABAR, NIGERIA
}

\author{
*W.O. Ndifon, *D.S.T. Ogaji and **S.J. Etuk \\ *Departments of Community Medicine ${ }^{1}$, ${ }^{* *}$ Obstetrics and Gynaecology, \\ University Of Calabar Teaching Hospital, Calabar, Nigeria
}

\begin{abstract}
Background - There has been increased concern on human sexuality, especially with respect to contraception and the control of sexually transmissible infections. There is need to identify the sociodemographic characteristics that influence sexual behaviour and contraceptive use among young women. Methods - A descriptive cross sectional study that focused on the socio-demographic characteristics, sexuality, knowledge and use of modern contraceptive technology as well as interventions taken in the event of inadvertent pregnancy was conducted. A structured, close- ended questionnaire was randomly administered to 195 female nursing students with 60, 65 and 70 of them in their first, second and third year respectively.
\end{abstract}

Results - Majority (76.7\%) of the students were in the age bracket of 20 - 24years. While $65.6 \%$ of them were sexually active, only $54.9 \%$ had knowledge of family planning. Condom was the commonest contraceptive used (37.4\%) and the main reasons were that of effectiveness (31.8\%) and safety (30.3\%). There was a significant relationship between respondents with multiple sexual partners and incidence of unwanted pregnancies $(p=0.003)$. The majority (51.2\%) of those with unwanted pregnancies resorted to induced abortion.
Conclusion - In view of the high prevalence of induced abortion among the respondents, current nursing training programmes need to be reviewed to meet the peculiar reproductive health needs of female student nurses.

Key words - Sexuality, Contraception, unintended pregnancy, school of nursing.

\section{INTRODUCTION}

Risky sexual behaviour, sexually transmitted infections (STIs), unwanted pregnancies, unsafe abortions and their complications still remain the major health problems of young adults worldwide ${ }^{1-6}$. WHO estimates that there are approximately 333 million cases of curable STIs per annum of which 65 million occur in sub-Sahara Africa. For women aged 15 - 44 years, the STIs excluding HIV, are the second commonest cause of healthy life lost. The advent of HIV infection has highlighted the importance of infection spread by the sexual route, especially among young adults in developing countries?. For instance, out of an estimated 11.8 million people aged $15-24$ years who were living with HIVIAIDS at the end of 2001, 8.6 million (73\%) of them were from sub-Sahara Africa. More than $50 \%$ of all new HIV infections occur among people under age 25 with infection rates among girls being five times higher than among young men in some African countries ${ }^{8}$. Most infections in young women are the 
result of unprotected sex and reflect a power imbalance between women and men in negotiating or controlling sexual interactions, especially with affluent older men. An average of eight percent of all pregnancies in Nigeria are unintended and majority occur among the unmarried. The commonest reasons for not wanting these pregnancies are bad timing, desire to continue schooling and the high cost of education; and the commonest method of resolving unwanted pregnancy is by abortion ? The incidence of induced abortion in Nigeria is put at 25 per 1000 women of reproductive age per year. There are approximately 610, 000 abortions performed in Nigeria annually, 60\% of which are unsafe, resulting in an abortion mortality rate of 120 deaths per 100,000 live births ${ }^{10}$. Apart from being currently the highest contributor to maternal mortality in our environment, unsafe abortion quite often results in lifelong sequelae such as menstrual dysfunction, cervical incompetence, ectopic pregnancy, chronic pelvic infection and infertility ${ }^{8,11}$.

Young women engage in sex for various reasons including fulfilling marital obligations, enhancing marriage prospects by proving their fertility to their future husbands and for financial benefits ${ }^{12}$.

Female student nurses face peculiar reproductive health challenges. Firstly, being young adults, majority aged 1524 years, many are sexually active, some with multiple partners with the risks of STIs, unplanned pregnancies, unsafe abortions with grave sequelae ${ }^{13}$.

Secondly, unlike their age-mates in tertiary institutions, students in certificate - awarding schools of nursing are, by policy, not permitted to get pregnant, regardless of their marital status. Those who become pregnant face sanctions ranging from demotion to expulsion. These students are thus faced with a dilemma: to get pregnant and lose a training opportunity or terminate the pregnancy and continue schooling with the risk of suffering the sequelae of unsafe abortion which include infertility among others. Those with past history of unsafe contraceptive practices are further pressurized to delay childbearing, often by the same unsafe methods, until graduation. This further decreases their chances of having children in future. Research has shown that, despite increased concern about human sexuality especially with regards to fertility regulation and control of sexually transmitted infections, the knowledge with the use of safe modern contraceptives is still discouragingly low even among students in tertiary institutions ${ }^{14,15}$.

Therefore, female student nurses while meeting their sexual needs, need to use contraceptive methods that are not only safe in the short term, but will also preserve their fertility for future childbearing 16,17 . This study was conducted to understand the sexual behaviour and contraceptive practices among female student nurses with special interest in interventions adopted following contraceptive failure. This information should guide the relevant authorities on the review of the current policy prohibiting married student nurses from getting pregnant while encouraging contraceptive methods that are most appropriate for the unmarried but sexually active ones. 


\section{SUBJECTS AND METHODS}

The Cross River State School of Nursing Calabar, south eastern part of Nigeria, was used for the study. It is one of the two schools of nursing in the city, the other being the University of Calabar Teaching Hospital School of Nursing. The state school was chosen because at the time of the study it had students in all the three years of training, and had a larger population than the other. This larger population yielded adequate sample size required for the study. The school is a certificae - awarding institution with a population of 210 students 205 females and five males.

The questionnaire was developed after due consultation with colleagues working on female reproductive health and review of relevant literature. It was modified after being pilot- tested on 20 female students in a school similar to the study school but in a different part of the city.

Before commencement of the study, permission was obtained from the school authorities. Informed consent was also obtained from the students.

The students' nominal roll served as sampling frame. With each year of study serving as a stratum, stratified random sampling was used to select 200 female students with 65,65 , and 70 of them in their first, second and third years of study respectively.

The data for the survey were collected in April, 2004 using a selfadministered questionnaire with closed questions. The questions focused on the socio-demographic characteristics of the respondents, their sexual practices, contraceptive methods and interventions in the event of contraceptive failure. To elicit the co-operation of the respondents, the objectives and potential benefits of the study were explained to them and they were encouraged to write only the truth. To ensure confidentiality, no names were required and the questionnaires were filled in the classrooms, outside the view of their class mates, in the absence of the teachers, and under the supervision of the authors. Of a total of 200 students recruited into the actual study, 195 $(97.5 \%)$ correctly completed the questionnaire. Data analysis was done using the EPI-INFO version 2002 software for the frequency distribution and Chi-square analysis. Level of significance was set at $<0.05$.

\section{RESULTS}

Of the 210 copies of the questionnaires administered, 195 were returned correctly filled, giving a response rate of $92.9 \%$. Majority of the respondents $(67.7 \%)$ were in the age bracket of 20 - 24 years, while $16.4 \%$ were aged between $15-19$ years and $15.9 \%$ were aged 25 or more years. Most (89.2\%) of them were unmarried, and a majority (75.4\%) of them were sponsored by their parents. The students were nearly evenly distributed into the three years of study.

More than half $(54.9 \%)$ of the students were aware of contraception and the senior married students were more aware than the junior unmarried ones $(P<0.05)$.

Table 1 shows that majority (65.7\%) of the students were sexually active, with a few (2.6\%) having more than one sex partner. The table reveals that the unmarried junior students sponsored by persons other than their parents tended to have multiple sex partners. 
Table 1: Number of sexual partners, according to socio-demographic characteristics of respondents $(\mathrm{N}=195)$

\begin{tabular}{|c|c|c|c|c|}
\hline \multirow[t]{2}{*}{ CHARACTERISTIC } & \multicolumn{3}{|c|}{ NUMBER OF SEXUAL PARTNERS } & \multirow[b]{2}{*}{ TOTAL } \\
\hline & NIL & 1 & $>1$ & \\
\hline AGE (YEARS) & FREQ. (\%) & FREQ. (\%) & $\begin{array}{c}\text { FREQ. } \\
\text { (\%) }\end{array}$ & FREQ. (\%) \\
\hline $15-19$ & $12(37.5)$ & $19(59.4)$ & $1(3.1)$ & $32(100)$ \\
\hline $20-24$ & $51(38.6)$ & 78 (59.1) & $3(2.3)$ & $132(100)$ \\
\hline $25-29$ & 4 (12.9) & $26(83.9)$ & $1(3.2)$ & $31(100)$ \\
\hline \multicolumn{5}{|l|}{ MARITAL STATUS } \\
\hline NEVER MARRIED & $66(37.9)$ & $103(59.2)$ & $5(2.9)$ & $174(100)$ \\
\hline MARRIED & $1(4.8)^{+}$ & $20(95.2)$ & $0(0.0)$ & $21(100)$ \\
\hline \multicolumn{5}{|l|}{ YEAR OF STUDY } \\
\hline $1^{\mathrm{ST}}$ & $10(16.7)$ & $48(80.0)$ & $2(3.3)$ & $60(100)$ \\
\hline $2^{N D}$ & $33(50.8)$ & $29(44.6)$ & $3(4.6)$ & $65(100)$ \\
\hline $3^{R D}$ & $24(34.3)$ & $46(65.7)$ & $0(0.0)$ & $70(100)$ \\
\hline
\end{tabular}

SPONSORSHIP

\begin{tabular}{lcccc} 
PARENTS & $62(42.2)$ & $83(56.5)$ & $2(1.3)$ & $147(100)$ \\
\hline OTHERS * & $5(10.4)$ & $40(83.3)$ & $3(6.3)$ & $48(100)$ \\
\hline
\end{tabular}

${ }^{+}$Widow without a sexual partner

* Others: Relatives, husband, fiancé

The condom was the commonest contraceptive method used (37.4\%). This was followed, in decreasing frequency, by rhythm (27.7\%), withdrawal $(21.5 \%)$ abstinence (16.6\%) and oral pills (5.1\%). As shown in Table 2, respondent's age did not influence choice of conceptive method, but marital status, year of study and source of sponsorship did. 
TABLE 2: Contraceptive methods according to socio-demographic characteristics of respondents

\begin{tabular}{|c|c|c|c|c|c|c|}
\hline \multirow[t]{3}{*}{ CHARACTERISTIC } & \multicolumn{6}{|c|}{ CONTRACEPTIVE METHOD } \\
\hline & CONDOM & RHYTHM & WITHDRAWAL & ABSTINENCE & ORAL PILLS & TOTAL ${ }^{+}$ \\
\hline & FREQ. (\%) & FREQ. (\%) & FREQ. (\%) & FREQ. (\%) & FREQ. (\%) & FREQ. (\%) \\
\hline $\begin{array}{l}\text { AGE (YEAR) } \\
15-19\end{array}$ & $15(50)$ & $5(16.6)$ & $6(20)$ & $2(6.7)$ & 2(6.7) & $30(100)$ \\
\hline $20-24$ & $46(33.3)$ & $37(26.8)$ & $26(18.8)$ & $23(16.7)$ & $6(4.4)$ & $138(100)$ \\
\hline $25-29$ & $12(27.9)$ & $12(27.9)$ & $10(23.2)$ & $7(16.3)$ & $2(4.7)$ & $43(100)$ \\
\hline P-value* & $>0.05$ & $>0.05$ & $>0.05$ & $>0.05$ & & \\
\hline \multicolumn{7}{|l|}{ MARITAL STATUS } \\
\hline NEVER MARRIED & $65(35.3)$ & $42(22.8)$ & $36(19.6)$ & $31(16.9)$ & $10(5.4)$ & 184(100) \\
\hline MARRIED & $8(29.6)$ & $12(44.5)$ & $6(22.2)$ & 1(3.7) & $0(0.0)$ & $27(100)$ \\
\hline P-value & $>0.05$ & $<0.05$ & $>0.05$ & $>0.05$ & $>0.05$ & \\
\hline \multicolumn{7}{|l|}{ YEAR OF STUDY } \\
\hline 1ST & 28(41.2) & $15(22.1)$ & 13(19.1) & $9(13.2)$ & $3(4.4)$ & $68(10)$ \\
\hline 2ND & $18(27.7)$ & $16(24.6)$ & $11(16.9)$ & $17(26.2)$ & $3(4.6)$ & $65(100)$ \\
\hline 3RD & $27(34.6)$ & $23(29.5)$ & $18(23.1)$ & $6(7.7)$ & $4(5.1)$ & $78(100)$ \\
\hline P-value & $>0.05$ & $>0.05$ & $>0.05$ & $<0.05$ & $>0.05$ & \\
\hline \multicolumn{7}{|l|}{ SPONSOR-SHIP } \\
\hline PARENTS & $47(34.3)$ & $31(22.6)$ & $27(19.7)$ & $26(19.0)$ & $6(4.4)$ & $137(100)$ \\
\hline OTHERS & $26(35.1)$ & $23(31.1)$ & $15(20.3)$ & $6(8.1)$ & $4(5.4)$ & $74(100)$ \\
\hline P-value & $<0.05$ & $<0.05$ & $>0.05$ & $>0.05$ & $>0.05$ & \\
\hline
\end{tabular}

+ Some respondents marked more than one method

* Chi-Square test based on actual number of respondents. 
More of the married students than the unmarried ones used the rhythm method $(P<0.05)$. Second year students used abstinence more than students in other classes $(P<0.05)$, and those sponsored by relatives or spouses used the condom and rhythm methods more frequently than their parent-sponsored colleagues $(P<0.05)$. Effectiveness of contraceptive method was cited as the commonest reason (31.8\%) for its choice. This was closely followed by safety of method (30.3\%). Other reasons cited were religion (22.1\%), cost (14.4\%), and ease of use (3.6\%).

Out of the 128 sexually active respondents, 43 (33.6\%) reported unintended pregnancy. While all $(100 \%)$ of the five respondents with multiple sex partners had unintended pregnancy, less than a third (30.9\%) of those with only one partner reported unintended pregnancy. This difference was statistically significant $(\mathrm{P}<0.05)($ Table 3$)$.

Table 3: Relationship between number of sexual partners and unintended pregnancy

\begin{tabular}{ccccc} 
Sexual Partners & \multicolumn{2}{c}{ Unintended Pregnancy } & Total & P-Value \\
\hline & Yes Freq. (\%) & No Freq. (\%) & Freq. (\%) & \\
\hline$>1$ & $38(30.9)$ & $85(69.1)$ & $123(100)$ & \\
\hline & $5(100)$ & $0(0)$. & $5(100)$ & $<0.05$ \\
\hline
\end{tabular}

As shown in Table 4, age, marital status and school year did not significantly influence the prevalence of unintended pregnancy, but the source of sponsorship did as only $15 \%$ of the parent-sponsored students reported unintended pregnancy compared with $43.8 \%$ of those sponsored by non-parents $(P<0.05)$.

Table 4: Unintended pregnancy according to socio-demographic characteristics of respondents $(\mathrm{N}=195)$

\begin{tabular}{|c|c|c|c|c|}
\hline CHARACTERISTIC & \multicolumn{4}{|c|}{ UNINTENDED PREGNANCY } \\
\hline AGE (YEAR) & $\begin{array}{c}\text { YES } \\
\text { FREQ. (\%) }\end{array}$ & $\begin{array}{c}\text { NO } \\
\text { FREQ. (\%) }\end{array}$ & $\begin{array}{c}\text { TOTAL } \\
\text { FREQ. (\%) }\end{array}$ & P-values \\
\hline $\begin{array}{l}15-19 \\
20-24\end{array}$ & $\begin{array}{c}2(6.3) \\
33(25.0)\end{array}$ & $\begin{array}{l}30(93.8) \\
99(75.0)\end{array}$ & $\begin{array}{c}32(100) \\
132(100)\end{array}$ & \\
\hline $25-29$ & $8(25.8)$ & $23(74.2)$ & $31(100)$ & $P>0.05$ \\
\hline $\begin{array}{l}\text { MARITAL STATUS } \\
\text { NEVER MARRIED }\end{array}$ & $36(20.6)$ & $138(79.4)$ & 174(100) & \\
\hline MARRIED & $7(35.0)$ & $14(65.0)$ & $21(100)$ & $P>0.05$ \\
\hline $\begin{array}{l}\text { YEAR OF STUDY } \\
1^{\text {ST }} \\
2^{\mathrm{ND}} \\
3^{\mathrm{RD}}\end{array}$ & $\begin{array}{l}18(30.0) \\
12(18.5) \\
13(18.6)\end{array}$ & $\begin{array}{l}42(70.0) \\
53(81.5) \\
57(81.4)\end{array}$ & $\begin{array}{l}60(100) \\
65(100) \\
70(100)\end{array}$ & $P>0.05$ \\
\hline SPONSORSHIP & & & & \\
\hline PARENTS & $22(15.0)$ & $125(85.0)$ & 147(100) & \\
\hline OTHERS* & $21(43.8)$ & $27(56.2)$ & $48(100)$ & $\mathrm{P}<0.05$ \\
\hline
\end{tabular}

* $\quad$ Others $=$ Relatives, husband, fiancé. 
Induced abortion was the commonest (51.1\%) method of resolving unintended pregnancy by the students. This was followed by oral pills $(30.2 \%)$. More than eighteen percent (18.6\%) of the 43 students who reported unintended pregnancy did nothing.

Table 5 reveals that induced abortion was more frequent among the older, unmarried second year students and those sponsored by non-parents than their younger, married colleagues in other classes and sponsored by their parents. Emergency contraception was common among the younger, unmarried students sponsored by non-parents than among their older married colleagues.

Table 5: Method of resolving unintended pregnancy according to sociodemographic characteristics of respondents

\begin{tabular}{|l|cccc|}
\hline CHARACTERISTIC & \multicolumn{3}{c}{ METHOD OF RESOLUTION } \\
\hline & $\begin{array}{c}\text { INDUCED } \\
\text { ABORTION }\end{array}$ & ORAL PILLS & NOTHING & TOTAL \\
\hline AGE (YEAR) & FREQ. (\%) & FREQ. (\%) & FREQ. (\%) & FREQ. (\%) \\
\hline $15-19$ & $1(50.0)$ & $1(50.0)$ & $0(0.0)$ & $2(100)$ \\
$20-24$ & $16(48.5)$ & $12(36.4)$ & $5(15.1)$ & $33(100)$ \\
\hline $25-29$ & $5(62.5)$ & $0(0.0)$ & $3(37.5)$ & $8(100)$ \\
\hline MARITAL STATUS & & & & \\
\hline NEVER MARRIED & $19(52.8)$ & $13(36.1)$ & $4(11.1)$ & $36(100)$ \\
\hline MARRIED & $3(42.9)$ & $0(0.0)$ & $4(47.1)$ & $7(100)$ \\
\hline YEAR OF STUDY & & & & \\
$1^{\text {ST }}$ & $8(44.4)$ & $5(27.8)$ & $5(27.8)$ & $18(100)$ \\
\hline $2^{\text {ND }}$ & $8(66.7)$ & $4(33.3)$ & $0(0.0)$ & $12(100)$ \\
$3^{\text {RD }}$ & $6(46.1)$ & $4(30.8)$ & $3(23.1)$ & $13(100)$ \\
\hline
\end{tabular}

SPONSORSHIP

\begin{tabular}{lcccc} 
PARENTS & $10(45.5)$ & $10(45.5)$ & $2(9.0)$ & $22(100)$ \\
\hline OTHERS * & $12(57.1)$ & $3(14.3)$ & $6(28.6)$ & $21(100)$ \\
\hline
\end{tabular}

* Others: Relatives, husband, fiancé 


\section{DISCUSSION}

This study shows a high prevalence of sexual activity among student nurses in Calabar as $65.7 \%$ of the students are sexually active. This percentage is understandably higher than the figures found among secondary school students by other workers in Nigeria ${ }^{1,3,4,6,18-21}$. The respondents in the latter studies are relatively younger, almost all unmarried and therefore less sexually exposed. Arowojolu and others ${ }^{5}$ reported a higher percentage (87\%) of sexual activity among Nigerian undergraduates. Although some undergraduates and students of school of nursing may fall within the same age bracket, the presence of older, more mature, married and experienced postgraduates in the universities may influence the sexual behaviour of their undergraduate counterparts.

However an equally higher percentage $(77 \%)$ of sexual activity among younger girls, aged 13-18 years, was found by Evelyn and Osafu $^{2}$ in Benin. This must have been environmentally determined. Curiosity, peer pressure and difficult situations may lure adolescents into early, high risk sex.

The married respondents in this study may be engaging in sexual activity to fulfil marital obligations but their unmarried counterparts who are the majority (108 out of 128 or $84.4 \%$ ) are doing so probably to prove their fertility to their future husbands or for financial assistance to fund their education. Justifiable as these reasons may seem, the fact is that many female student nurses are engaging in high risk sex, since only about a third (37.4\%) of them were using the contraceptive method that prevents unintended pregnancy and STIs, namely the condom. This contraceptive method should form the plank of the contraceptive education that should be introduced in the first year in schools of nursing. Although the percentage of respondents with multiple sexual partners (2.6\%) is less than the mean of $30 \%$ reported by other workers in South west Nigeria ${ }^{1,2}$, multiple partnership is a high risk factor for STIs including HIV. This point needs to be emphasized in the sex education curriculum for student nurses.

Despite increased concern about human sexuality as evidenced by concerted efforts at fertility regulation and control of sexually transmitted infections, the use of modern contraceptives, especially the condom, is still discouragingly low. This was confirmed in this study as only $37.4 \%$ of the students reported condom use, corroborating the findings by other workers ${ }^{1,3,4,6}$. Low condom use is still persisting in spite of increasing level of awareness of its efficacy $^{1,5,22}$. Sexual intercourse with multiple partners and limited use of condom have grave health implications such as STIs and unwanted pregnancies which are often unsafely terminated. There is dire need for behavioural change communication concerning use of condom. Fewer student nurses (16.40\%) practised abstinence than their younger secondary school counterparts $(51.3 \%)$ studied by lyaniwura and Salako $^{21}$. It will be unrealistic to expect the older married student nurses to abstain from sex. However, it is encouraging that more of the unmarried students (16.9\%) practised abstinence than their married counterparts (3.7\%). Premarital sexual abstinence is one of the messages of the anti-AIDS campaign and needs to be sustained.

Although the unintended pregnancy rate of $22.1 \%$ in this study is higher than the national average of eight percent ${ }^{9}$, it is comparable with findings by other workers in South Eastern Nigeria ${ }^{4,20,22}$. Limited condom use and especially multi-partnership are to blame, as evidence by the fact that all the respondents with multiple sexual 
partners reported unintended pregnancy. One of the most unfavourable outcomes of unplanned, unprotected sex is unintended pregnancy. Unlike in the past when pre-marital pregnancy used to result in compulsory marriage of the girl to the father of her child, today, due to western civilization and the erosion of traditional family and community values, young women are having greater freedom regarding their sexuality. The high cost of education and the desire to continue schooling for enhanced socio-economic status are also pressurizing young women to delay childbearing by resorting to induced abortion as the major method of resolving unwanted pregnancy ${ }^{9}$. It is therefore not surprising that out of the forty-three (43) respondents in this study, who reported unintended pregnancy, $22(51.2 \%)$ resorted to induced abortion. Varying abortion rates have also been reported by other workers in Southern Nigeria $4,5,19,22$.

This study has established that, although non-therapeutic abortion is illegal in Nigeria, majority of the student nurses with unintended pregnancy are resorting to clandestine abortion. It also confirms that young unmarried women are more likely than their older, married counterparts, to seek abortion. One of the major ways of controlling clandestine abortion in Nigeria is the provision of family planning services. However, despite the availability of these services, their use by the youths is still poor probably due to lack of adequate information about the efficacy of the methods, fear of side effects, shame, negative cultural attitudes and the judgmental attitude of service providers ${ }^{5}$. It is strongly recommended that family health clinics should be established within or near schools of nursing and the students encouraged to use them. Family life education should form part of the curriculum in the first year of training so that students are adequately and properly informed on reproductive health issues. Emphasis should be placed on contraceptive methods that are safe and capable of preserving the fertility of the students for future childbearing. More importantly the current policy of sanctioning pregnant student nurses irrespective of their marital status needs to be reviewed, for there is no guarantee of a student retaining her fertility after induced abortion ${ }^{23}$

As a long term measure, for nurses-in-training to enjoy the same privileges as their counterparts in other tertiary institutions, certificate awarding programmes in schools of nursing should gradually be replaced by degree- awarding programmes in the universities as is the case in some western countries like the United Kingdom. This will enable pregnant student nurses carry their unborn babies till delivery. It is hoped that this paradigm shift in nursing education will reduce the rate of clandestine abortions and their attendant grave consequences among student nurses.

\section{REFERENCES}

1. Olufunmilayo I. Fawole, Michael C. Asuzu and S. Olu Oduntan. Survey of knowledge, Altitudes and Sexual Practices Relating to HIV infection/ AIDS among Nigerian Secondary School Students Afr $\mathrm{J}$ Reprod Health1999; 3(2):15-24

2. Unuigbe I. Evelyn and Ogbeide Osafu. Sexual Bahaviour and Perception of AIDS Among Adolescent Girls in Benin City, Nigeria. Afr $\mathrm{J}$ Reprod Health 1999; 3(1): 39-44.

3. Oladimeji Oladepo and William Briger, Sexual Attitudes and Behaviour of male Secondary school Students in Rural and Urban Areas of Oyo State, Nigeria. Afr $\mathrm{J}$ Reprod Health 2000; 4(2): 21-34.

4. IC Anochie and EE Ikpeme. Prevalence of Sexual Activity 
and Outcome among female Secondary School Students in Port Harcourt, Nigeria. Afr $J$ Reprod Health 2001: 5(2): 63-67.

5. AO Arowojolu, AO Roberts and MA Okunola, Sexuality Contraceptive choice and AIDS Awareness among Nigerian Undergraduates. Aft $\mathrm{J}$ Reprod Health 2002; 6(2): 60-70.

6. Gail B. Slap, Lucy Lot, Bia Huang, Comfort A. Daniyan, Therese M. Zink, Paul Succop. Sexual behaviour of adolescents in Nigeria: Cross Sectional Survey of Secondary School Students. BMJ W Afr 2003; 6(1): 202-208.

7. Adler MW. ABC of Sexuality Transmitted Diseases, $4^{\text {th }}$ ed. London: BMJ publishing Group 1999: Рp 1-3.

8. Lamptey P. Facing the HIVIAIDS Pandemic Pop Bull 2002: 57(3): 1-35

9. Okonofua FE. Unwanted Pregnancy, Unsafe Abortion and the law in Nigeria. Trop J Obstet Gynaecol 19: Suppl 1, 2002: 515-517.

10. Adinma JIB. An Overview of the Global Policy Consensus on Women's sexual and reproductive rights: The Nigerian Perspective. Trop Obstet Gynaecol 19: Suppl 1. 2002: 59-512.

11. Abasiattai A. Current Concepts in Contraception. The Syringe Magazine of the Calabar University Medical Students Association, $6^{\text {th }}$ ed., 2003: 33-37.

12. Meekers D and Calves A. Gender Differentials in Adolescent Sexual Activity and Reproductive Health Risks in Cameroun. Afr J Reprod Health 1999; 3(2): 51-67.

13. McCauley AP and Salter C. Meeting the Needs of young Adults. Pop Reports 1995; series J (41) 3-43.
14. NPC: Nigerian Demographic and Health Survey, 1999

15. UNDP/UNFPAWHO: Sexual behaviour of young people; progress in human reproduction research Vol. 41, 1996.

16. WHO: Reproductive HealthStrategy for the African Region, 1998 - 2007.

17. FMOH: National Reproductive Health Policy and Strategy to achieve quality reproductive and sexual health for all Nigerian, Abuja, 2001.

18. Bassey EA, Abasiattai AM, Asuquo EE, Udoma ES, Oyo-Ita A. Awareness, attitude and practice of contraception among Secondary School girls in Calabar, Nigeria. Niger $\mathrm{J}$ Med. 2005 Apr-Jun: 14(2): 146-50.

19. Aziken ME, Okonta PI, Ande AB. Knowledge and perception of emergency contraception among female Nigerian Undergraduates. Int Fam Plan Perspective. 2003 Jun: 29(2): 84-7.

20. Adinma JI, Agbai AO, Okeke AO, Okaro JM, Contraception in Nigerian School girls. Adv. Contraception. 1999; 15(4): 283-91.

21. C A Inyaniwura and AA Salako. Sexual Activity and Condom use by In-School Youths in Sagamu, Ogun State. Nig Med. Pract. 2005; 48(4): 103-107.

22. Ikeme AC, Ezegwui $\mathrm{HU}$, Uxzodimma AC. Knowledge, attitude4 and use of emergency contraception among female undergraduates in Eastern Nigeria. J. Obstet Gynaecol. $2005 \mathrm{Jul} ; 25(5):$ 491-3

23. Asukwo D. Ekanem, Saturday J. Etuk, Edem J. Udoma and Imaobong A. Ekanem. Fertility Profile Following Induced Abortion in Calabar, Nigeria

24. Trop J Obstet Gynaecol 2003; 20(2):89-92 